\title{
BMJ Open The economic burden of infections following intramedullary nailing for a tibial shaft fracture in England
}

\author{
Thibaut Galvain (D) , ${ }^{1}$ Abhishek Chitnis, ${ }^{2}$ Konstantina Paparouni, ${ }^{3}$ Cindy Tong, ${ }^{4}$ \\ Chantal E Holy, ${ }^{2}$ Peter V Giannoudis ${ }^{5,6}$
}

To cite: Galvain T, Chitnis A, Paparouni K, et al. The economic burden of infections following intramedullary nailing for a tibial shaft fracture in England. BMJ Open 2020;10:e035404. doi:10.1136/ bmjopen-2019-035404

- Prepublication history and additional material for this paper are available online. To view these files, please visit the journal online (http://dx.doi. org/10.1136/bmjopen-2019035404).

Received 30 0ctober 2019

Revised 11 June 2020

Accepted 19 June 2020

Check for updates

(C) Author(s) (or their employer(s)) 2020. Re-use permitted under CC BY-NC. No commercial re-use. See rights and permissions. Published by BMJ.

For numbered affiliations see end of article.

Correspondence to Dr Thibaut Galvain; tgalvain@its.jnj.com

\section{ABSTRACT}

Objectives Determine the impact of infections on direct costs and healthcare resource use in England for patients undergoing intramedullary nailing (IMN) for tibial shaft fractures.

Design Non-concurrent cohort based on retrospectively collected data with 2-year follow-up.

Setting England.

Participants The study population included adult patients ( $\geq 18$ years) in England with a diagnosis of tibial shaft fracture (International Classification of Diseases-10, S822) in the inpatient setting between May 2003 and June 2017 followed by a procedure for IMN for tibial shaft fracture within 30 days. Patient data were derived from the Clinical Practice Research Datalink linked to National Health Service Hospital Episode Statistics datasets.

Primary independent variable Infection.

Primary and secondary outcome measures The primary outcome was total inpatient costs from index stay admission through 1 year of follow-up. Secondary outcome included cumulative total healthcare costs, and resource utilisation at 30 days, 90 days, 1 year and 2 years.

Results Overall, 805 patients met the inclusion criteria. At index inpatient stay, $3.7 \%$ had a post-IMN infection, rising to $11.7 \%$ at 1 year. One-year inpatient costs were $80 \%$ higher for patients with infection $(p<0.001)$. Total costs were estimated to be $£ 14756$ (95\% Cl $£ 13123$ to $£ 16593)$ for patients with infection versus $£ 8279$ (95\% $\mathrm{Cl} £ 7946$ to $£ 8626)$. Length of stay (LOS), readmission and reoperation were the key drivers of healthcare costs (all $\mathrm{p}<0.001$ ). After adjustment, LOS was higher by $109 \%$ (95\% Cl 62\% to $169 \%$ ), from 10.5 days to 21.9 days, for patients with infection. The odds of being readmitted or requiring reoperation were higher by 5.18 times $(95 \%$ $\mathrm{Cl} 3.01$ to 9.13$)$ and 2.47 times (95\% $\mathrm{Cl} 1.48$ to 4.09$)$, respectively, for patients with infection versus those without infection.

Conclusions Post-IMN infection significantly increases inpatient costs, LOS, readmissions and reoperations associated with tibial fracture fixation. Healthcare burden could be reduced through novel surgical site infection prevention strategies.

\section{INTRODUCTION}

Tibial shaft fractures are the most common type of long-bone fracture. They can be either closed fractures, where the skin remains

\section{Strengths and limitations of this study}

- This is the first study to quantify the healthcare resource burden of infections following tibial shaft fractures treated with intramedullary nailing in England.

- The study had a long-term and cross-sector perspective that included inpatient, hospital outpatient and primary care parameters.

- This study only considered patients with complete follow-up, thus, excluding very severe patients with short life expectancy.

- Some costs were not directly available from the Clinical Practice Research Datalink dataset and were sourced from published national sources.

- The study relied on clinical codes to identify superficial and deep infections which may be subject to coding errors and misclassifications.

intact, or open fractures (accounting for $25 \%$ of all tibial shaft fractures) where the skin is broken. ${ }^{1}$

Intramedullary nailing (IMN) is a common surgical treatment for this type of injury. Infection after IMN is a potential complication, especially in severe open fractures, that can delay wound healing and fracture repair. $^{2-5}$ If left untreated, an infection may lead to permanent loss of function of the affected limb. ${ }^{236}$ Open fractures are especially prone to infection due to wound exposure to the environment with the risk of infection depending on the severity of soft tissue damage. ${ }^{4}$ Patients with cases of extreme and uncontrollable infection may require limb amputation to prevent deterioration and maintain quality of life. ${ }^{2}$

Infections following fracture fixation are subclassified according to the depth of the infection: superficial (subcutaneous region), deep (muscle/fascial region) or organ/space infections. ${ }^{7}$ However, there is debate over the usefulness of these terms, as they can be arbitrary depending on the location of an infection. ${ }^{6}$ A US study reported an infection rate 
of $2 \%$ after IMN for closed fractures compared with $7.1 \%$ for open fractures. ${ }^{8}$ A Belgian study reported an infection rate of $4.3 \%$ in patients with open or closed fractures, of which $1.4 \%$ were deep. ${ }^{9}$ In a meta-analysis of studies investigating prophylactic antibiotic use in patients with open tibial fractures treated with IMN, the risk of infection increased with severity of the fracture, rising to over $31 \%$ among patients with the most severe injury (and who received systemic antibiotics only). ${ }^{5}$

Patients who experience infection are more likely to require additional surgeries, extended hospital stays and extensive treatment for postoperative infection..$^{2-46}$ There are only a limited number of studies, however, which compare healthcare resource utilisation and treatment costs for tibial shaft fractures with and without postsurgical infection across Europe. In a Belgian study, healthcare costs were five times higher and total length of stay (LOS) six times longer for open tibial shaft fracture patients with deep infection versus those with no infection. ${ }^{10}$ In Denmark, the average direct cost of treating a severe open tibial shaft fracture was estimated to be $€ 49$ 817 increasing to $€ 81155$ when infection occurred. In patients treated within 7 days of their injury, infection increased the average direct cost and LOS by $124 \%$ and $135 \%$, respectively. ${ }^{11}$

The aim of this non-concurrent cohort study was to determine the impact of infections on healthcare costs and resource utilisation for patients undergoing IMN for tibial shaft fractures from the perspective of National Health Service (NHS) England.

\section{MATERIALS AND METHODS}

\section{Study design and setting}

This was a non-concurrent cohort study based on retrospectively collected data of patients in England who underwent IMN for tibial shaft fracture (open or closed) and were followed-up for 2 years. Data derived from the Clinical Practice Research Datalink (CPRD) linked to National Health Service (NHS) Hospital Episode Statistics (HES) and NHS reference costs were used to calculate costs and healthcare resource utilisation associated with infections (superficial or deep) following IMN.

The CPRD database is an anonymised longitudinal dataset of over 11.3 million medical records from over 600 primary care practices across the UK. ${ }^{12}$ It includes all visits to primary care and other healthcare professionals, reasons for visits, diagnoses observations, medical history, test results, referrals and prescriptions. ${ }^{12}$ For this study, HES data relating to admissions to, or attendances at, English NHS healthcare providers were used (HES Admitted Patient Care data).

\section{Patients}

The study population included adults (aged $\geq 18$ years) who were diagnosed with an isolated or not tibial shaft fracture (International Classification of Diseases[ICD]-10 code: S82.2) between May 2003 and June 2017 and who subsequently underwent IMN within 30 days of diagnosis. Inclusion and exclusion criteria and patient attrition flow are depicted in figure 1 .

Infections were identified using clinical diagnosis codes either from the inpatient setting (ICD-10, Office of Population Censuses and Surveys[OPCS] codes) or the primary care setting (read codes) (see online supplementary file S1). Only patients with an infection occurring on (or after) day 2 following the index date were considered eligible for the infection cohort, as this would exclude infections that were present preoperatively. For subgroup analysis, diagnosis codes were categorised into either deep or superficial infections and open or closed fractures based on medical knowledge.

\section{Data collection}

The primary outcome of this study was total inpatient costs (Healthcare Resource Group (HRG), unbundled HRG and specialised care) accrued beginning from index stay admission through 1 year of follow-up postdischarge from the index stay. Secondary endpoints included cumulative total healthcare costs and resource utilisation for 30 days, 90 days, 1 year and 2 years of follow-up postdischarge of the index stay. Total healthcare costs comprised inpatient, hospital outpatient and primary care costs (consisting of consultations, prescriptions and tests/investigations). Healthcare resource utilisation included LOS, readmissions, reoperations, days in intensive care unit, hospital outpatient visits, diagnostic tests and primary care visits. Time to infection was an additional secondary outcome.

\section{Resource use and costs}

Healthcare cost data were estimated based on the healthcare resource utilisation reported in CPRD/HES and the unit cost associated with each service from an NHS perspective. In England, NHS provides preventive medicine, primary care and hospital services to $88 \%$ of the citizens. Responsibility for publicly funded healthcare remains with the Secretary of State for Health, supported by the Department of Health. ${ }^{13}$ Hospitals are reimbursed by NHS according to the amount and type of activity that they perform using HRGs. ${ }^{14}$

\section{Inpatient costs}

The 2017/2018 HRG Reference Costs Grouper software was used to generate HRG codes for each inpatient admission. ${ }^{15}{ }^{16}$ Each HRG code was assigned an appropriate cost from NHS Reference Costs, ${ }^{17}$ using admission method, LOS, trim point and the patient classification to associate the relevant costs. ${ }^{151819}$ Inpatient stays were considered as long stays for admissions lasting $\geq 2$ days in line with NHS reference costs. ${ }^{18}{ }^{20}$ Unbundled HRGs were automatically generated by the Grouper software and assigned relevant costs. ${ }^{17}$ Specialised care episodes were identified using the Prescribed Specialised Services Tool 2017/18 software and top-up costs were applied as a percentage increase to the HRG cost. ${ }^{21}$ 


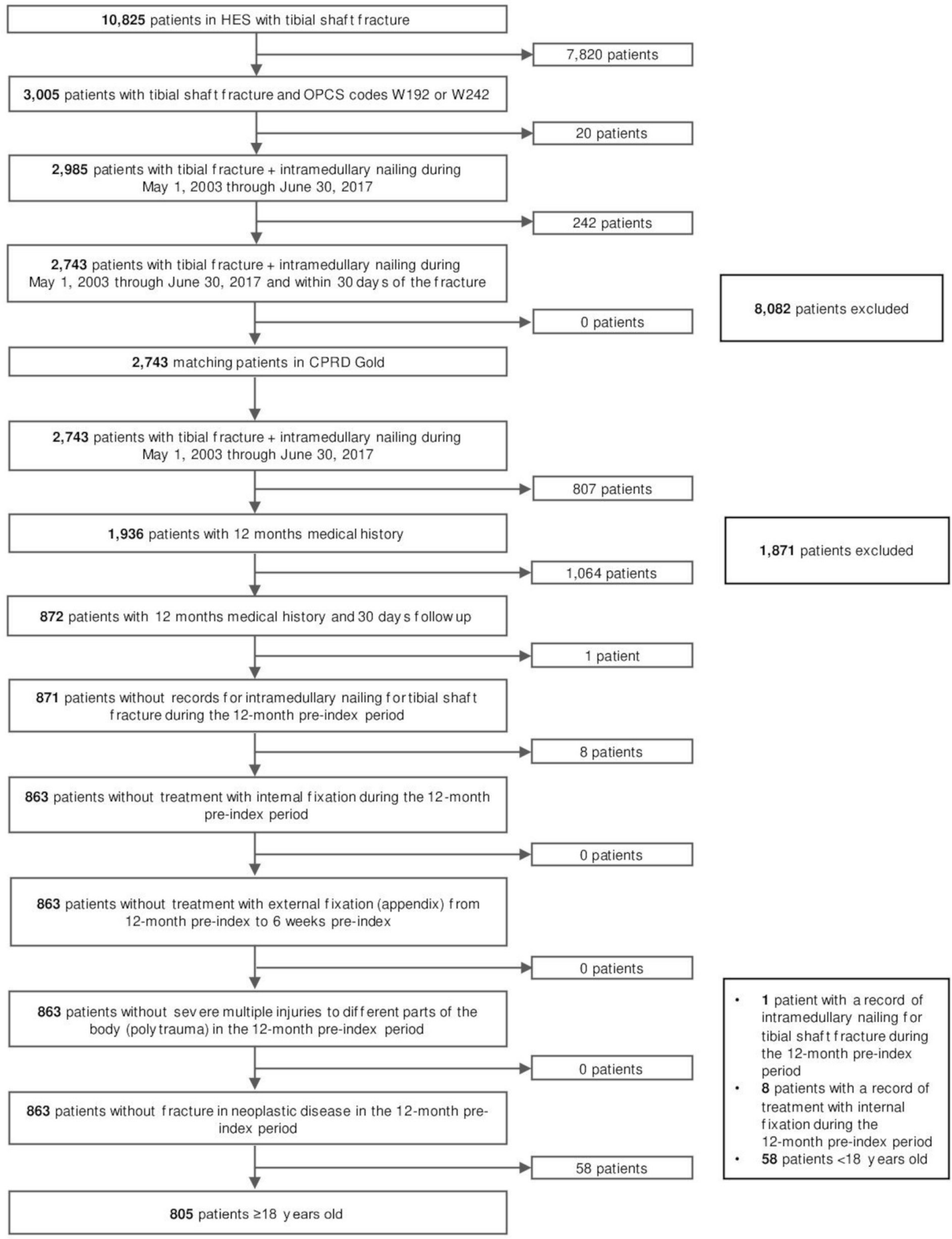

Final cohort

$N=805$

Figure 1 Patient screening and enrolment according to the study inclusion/exclusion criteria. CPRD, Clinical Practice Research Datalink; HES, Hospital Episode Statistics; OPCS, Office of Population Censuses and Surveys.

Hospital outpatient costs

Outpatient costs were derived from the CPRD referral file where the referral type was classified as 'outpatient' and matched against NHS reference costs for the same or closest matching specialty. ${ }^{17} 19$

\section{Primary care costs}

Consultations from the CPRD consultations file were categorised based on the setting (clinical, surgery, home, telephone and administrative) and healthcare provider (doctor, nurse and other professional). Costs 
were sourced from the Unit Costs of Health and Social Care. $^{22}$

Laboratory and diagnostic tests from the CPRD tests file were manually matched to the closest NHS test category and assigned NHS Reference Costs. ${ }^{18}$

Medication categories were based on British National Formulary classifications as recorded in the CPRD therapy file, and unit costs were obtained using the ${ }^{23}$ Prescription Cost Analysis 2017 using the mean subparagraph cost associated with each medication. ${ }^{23}$

\section{Follow-up period and cohort definitions}

Follow-up time was calculated as the difference between the index discharge date and the last date of observation. Only patients with follow-up data at the relevant time point were included in the analysis.

\section{Statistical analyses}

All analyses were conducted using R Studio V.3.4.3. Statistical significance was set a priori at $\mathrm{p}<0.05$ (two-sided). Study variables were analysed descriptively. Time-toinfection was depicted graphically using the Kaplan-Meier estimator. Unadjusted comparisons of patient demographics, comorbidities and medication use between groups were performed using t-tests for continuous variables that were approximately normal, and Wilcoxon rank-sum tests for continuous variables that were not normally distributed. Prespecified subgroup analyses allowed for stratification of results according to type of fracture (open vs closed) or type of infection (superficial vs deep).

Generalised linear models were used to adjust for confounding, to isolate the association between surgical site infection and the outcomes. Covariates were identified a priori as risk factors for the study outcomes based on clinical knowledge. A backwards stepwise procedure was applied according to the Akaike information criterion. Missing data were not imputed. Except for in the sensitivity analyses, patients with missing data were excluded from analyses.

Sensitivity analyses at all time points were conducted using data from the subgroup of patients who had completed 2-year follow-up for total costs, LOS, readmission (rate and mean count) and reoperation (rate and mean count).

\section{Patient and public involvement}

Patients or the public were not involved in the design, or conduct, or reporting or dissemination plans of our research.

\section{RESULTS}

Patient baseline characteristics

Of the 10825 patients identified as having suffered a tibial shaft fracture, 3005 received IMN. Of these, a total of 805 patients met the inclusion criteria and were included in the study (figure 1). The mean follow-up time was 4.8 years. The mean (SD) age was 40.8 (17.2) (see table 1 for index stay; online supplementary file S2). A majority of patients were men $(n=590 ; 73.3 \%)$ and most had suffered a closed $(n=663 ; 82.4 \%)$ tibial shaft fracture. Among patients with an open fracture, a significantly higher proportion of patients $(10.6 \%)$ experienced an infection compared with $2.3 \%$ of patients with a closed fracture $(\mathrm{p}<0.001 ;$ table 1$)$.

\section{Infection rates}

During the index stay, 30 patients $(3.7 \%)$ experienced an infection. Among patients with 30 day, 90 day, 1 year and 2 years postdischarge follow-up data, infection rates were respectively: $8.0 \%, 9.2 \%, 11.7 \%$ and $13.4 \%$ (figure 2 ).

\section{One-year inpatient costs}

Among patients with index stay plus 1-year postdischarge data $(\mathrm{N}=686)$, the mean 1-year total inpatient cost was significantly higher among patients who experienced an infection ( $£ 15580 ; \mathrm{n}=80$ ) compared with patients without infection $(£ 7746 ; \mathrm{p}<0.001)$. After adjusting for fracture type (open/closed), age, smoking status, index year, diabetes, COPD, inpatient waiting time for surgery and compartment syndrome, mean costs were 80\% (95\% CI: 58\%, 104\%) higher, respectively (£13 672 [95\% CI: $£ 12$ 122, £15 420] versus £7616 [95\% CI: £7301, £7944]; $\mathrm{p}<0.001$ ), (figure 3).

\section{One-year total costs}

Adjusted total costs were $£ 14756$ (95\% CI £13 123 to $£ 16$ 593) among patients who experienced an infection versus $£ 8279$ (95\% CI $£ 7946$ to $£ 8626$; $p<0.001$ ) in patients without infection-a $78 \%$ increase in total costs as a result of infection (95\% CI 57\% to 102\%) (figure 3).

\section{One-year healthcare resource use}

For the majority of healthcare resource categories, the presence of infection was associated with a statistically significant increase in resource use versus no infection (table 2). Key drivers of increased costs were LOS, readmission and reoperation rates, which were all significantly higher in patients with infections (all $\mathrm{p}<0.001$ ). After adjustment, LOS was increased by $109 \%$ (95\% CI $62 \%$ to $169 \%$ ) from 10.5 days to 21.9 days. The odds of being readmitted or requiring reoperation due to infection was increased by 5.18 times (95\% CI 3.01 to 9.13 ) and 2.47 times (95\% CI 1.48 to 4.09 ), respectively.

\section{Total costs from index stay to 2-year follow-up}

At all-time points, mean total costs were statistically significantly higher for patients with an infection compared with those without $(\mathrm{p}<0.001)$ (figure 4$)$. Adjusted mean total costs of care in patients with infection versus no infection over time were: $£ 11257$ versus $£ 7017$ at 30 days; $£ 11949$ versus $£ 7423$ at 90 days and $£ 16626$ versus 99439 at 2 years (all $\mathrm{p}<0.001)$. 
Table 1 Patient demographic and clinical characteristics at index

\begin{tabular}{|c|c|c|c|c|}
\hline & \multirow[b]{2}{*}{$\begin{array}{l}\text { All enrolled } \\
\text { patients }(\mathrm{N}=805)\end{array}$} & \multicolumn{3}{|l|}{ Index stay } \\
\hline & & $\begin{array}{l}\text { No infection } \\
(\mathrm{N}=775)\end{array}$ & $\begin{array}{l}\text { Infection } \\
(\mathrm{N}=30)\end{array}$ & $P$ value \\
\hline Age (years), mean (SD) & $40.8(17.2)$ & $40.7(16.8)$ & $43.0(23.9)$ & 0.61 \\
\hline Gender, n (\%) & & & & 0.84 \\
\hline Charlson score, median (range) & $0.00(3.00)$ & $0.00(2.00)$ & $0.00(3.00)$ & $<0.001$ \\
\hline Smoker, n (\%) & $256(31.8)$ & $247(31.9)$ & $9(30.0)$ & 0.99 \\
\hline Diabetes, n (\%) & $27(3.4)$ & $27(3.5)$ & $0(0.0)$ & 0.62 \\
\hline COPD, n (\%) & $8(1.0)$ & $8(1.0)$ & $0(0.0)$ & 1.00 \\
\hline \multicolumn{5}{|l|}{ Index episode } \\
\hline $\begin{array}{l}\text { Inpatient waiting time (days) for surgery, } \\
\text { mean (SD) }\end{array}$ & $1.4(2.4)$ & $1.4(2.4)$ & $0.70(2.4)$ & 0.14 \\
\hline Fracture type, n (\%) & & & & $<0.001$ \\
\hline Open fracture & $142(17.6)$ & $127(16.4)$ & $15(50.0)$ & \\
\hline $\begin{array}{l}\text { Received } \geq 1 \text { prescription for antibiotics in } \\
\text { the } 12 \text { months prior to the index stay, } \mathrm{n}(\%)\end{array}$ & $60(7.5)$ & $60(7.7)$ & $0(0.00)$ & 0.16 \\
\hline $\begin{array}{l}\text { Received } \geq 1 \text { prescription for opioids in the } \\
12 \text { months prior to the index stay, } n(\%)\end{array}$ & $16(2.0)$ & $15(1.9)$ & $1(3.3)$ & 0.46 \\
\hline
\end{tabular}

COPD, chronic obstructive pulmonary disease.

Healthcare resource use from index stay to 2-year follow-up Multivariate analysis demonstrated that LOS, readmissions (rate and mean; figure 5) and reoperations (rate and mean; figure 6) were consistently higher at all timepoints among patients who experienced an infection compared with those who did not $(\mathrm{p}<0.001)$. At 30 days, infection increased the adjusted LOS from 8.9 days to 15.0 days and at 2 years from 11.3 days to 24.6 days (both $\mathrm{p}<0.001$ ). The

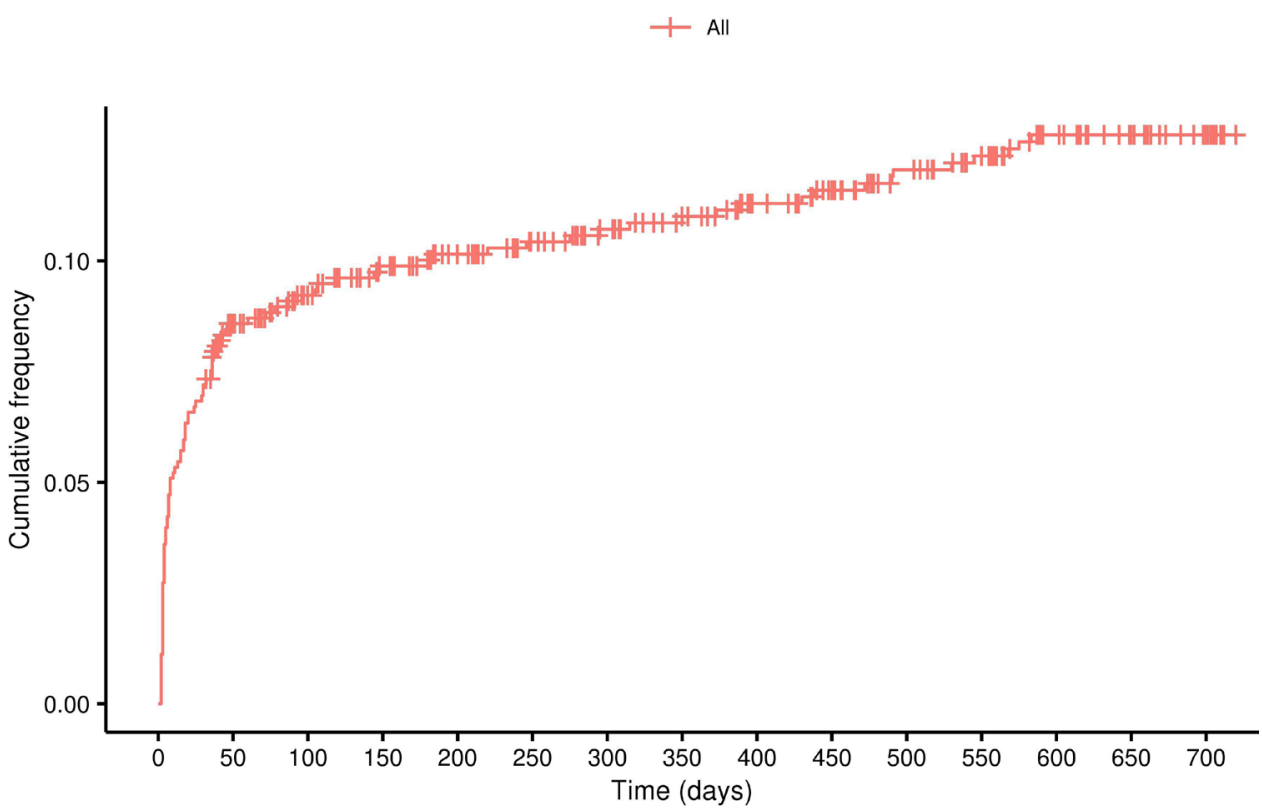

Figure 2 Cumulative percentage of infection events recorded postindex date. 


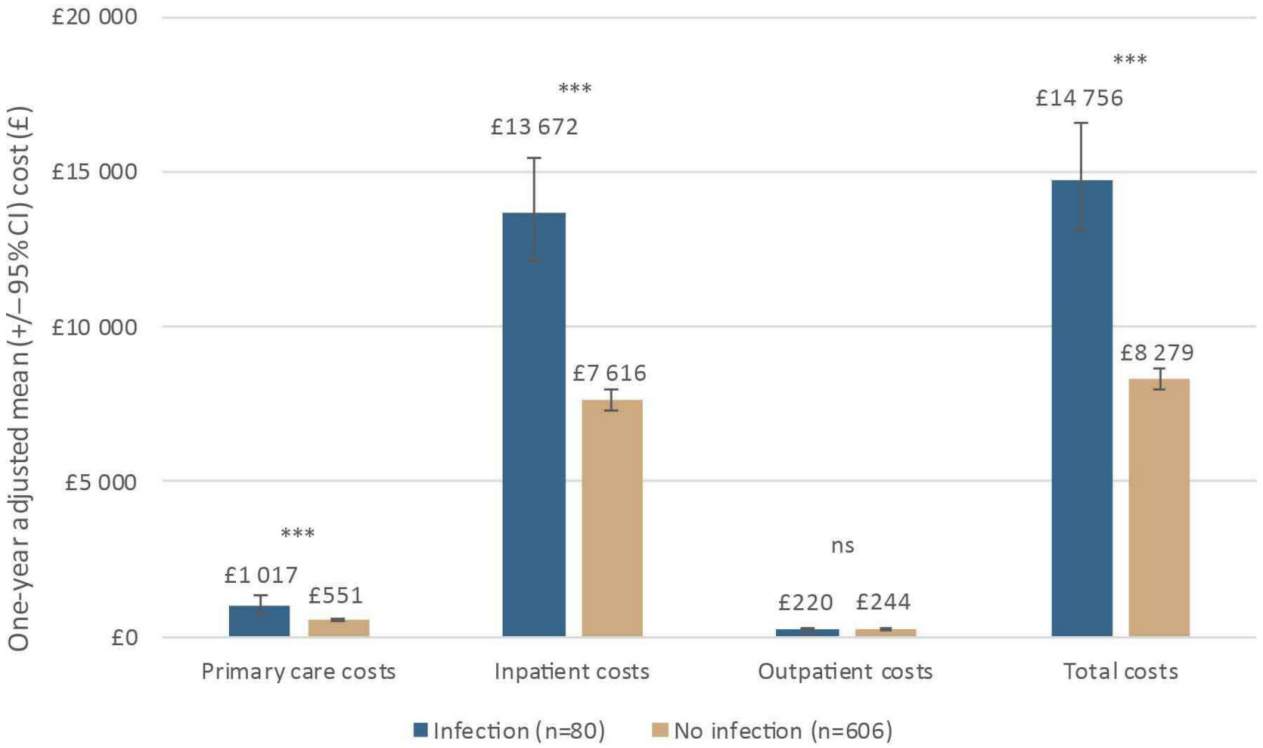

Figure 3 Breakdown of 1 year total costs by infection status (adjusted analysis); ${ }^{* \star *} p<0.001$. NS, not significant.

adjusted readmission rate increased from $7.1 \%$ at 30 days to $51.3 \%$ at 2-year follow-up in patients without infection compared with an increase from $44.1 \%$ to $77.6 \%$ in the infection group (figure 5). The adjusted reoperation rate increased from $1.3 \%$ at 30 days to $31.2 \%$ at 2 years in the absence of infection, whereas in the infection group, the rate increased from $11.5 \%$ to $49.0 \%$ (figure 6 ).

\section{Subgroup analyses}

Multivariate analysis by infection type resulted in mean 1-year inpatient costs of £7614, £12 814 and £15 513, respectively for no infection $(\mathrm{n}=606)$, superficial infection $(n=54)$ and deep infection $(n=26)$ (online supplementary file S2). Analysis by fracture type showed a higher 1-year infection rate among patients with open fractures $(27.4 \%)$ versus closed fractures $(8.6 \%)$. Mean adjusted inpatient costs at 1 year for patients with and without infection were $£ 19542$ versus $£ 9495$ for patients with open fractures and $£ 12178$ versus $£ 7278$ for patients with closed fractures.

\section{Sensitivity analyses}

A total of 588 patients (73\%) out of the 805 patients at index had data for the full 2-year follow-up period. Results for total costs, LOS, readmissions (rate and mean) and reoperations (rate and mean) at each time point were consistent with those of the primary analyses (online supplementary file S2).

\section{DISCUSSION}

This study used CPRD-linked HES data to determine the impact of infection on English healthcare costs and resource utilisation associated with patients undergoing IMN for tibial fracture. Infection rates at 1 year and 2 years (11.7\% and $13.4 \%$, respectively) were comparable with

Table 2 One-year healthcare resource use by infection status

\begin{tabular}{|c|c|c|c|}
\hline & \multicolumn{3}{|l|}{ Multivariate analysis } \\
\hline & $\begin{array}{l}\text { No infection }(\mathrm{N}=606) \\
\text { Mean }(95 \% \mathrm{Cl})\end{array}$ & $\begin{array}{l}\text { Infection }(\mathrm{N}=80) \\
\text { Mean }(95 \% \mathrm{Cl})\end{array}$ & $P$ value \\
\hline LOS, days & 10.5 (9.7 to 11.4$)$ & 21.9 (17.3 to 27.7$)$ & $<0.001$ \\
\hline ICU LOS, days & 0.01 (0.01 to 0.02$)$ & 0.01 (0.00 to 0.02$)$ & 0.91 \\
\hline Number of readmissions & 0.5 (0.5 to 0.6$)$ & 1.5 (1.2 to 1.8$)$ & $<0.001$ \\
\hline Readmission rate, $\%$ & 35.9 (32.1 to 39.9$)$ & 74.4 (63.4 to 83.0$)$ & $<0.001$ \\
\hline Number of reoperations & $0.2(0.2$ to 0.3$)$ & $0.6(0.5$ to 0.8$)$ & $<0.001$ \\
\hline Reoperations rate, \% & 20.3 (17.2 to 23.8$)$ & $38.6(28.3$ to 50.0$)$ & $<0.001$ \\
\hline Number of hospital outpatient referrals & 1.8 (1.6 to 2.1$)$ & 1.7 (1.2 to 2.1$)$ & 0.44 \\
\hline \multicolumn{4}{|l|}{ Primary care resource use } \\
\hline Number of primary care events & 30.9 (29.2 to 32.7$)$ & 45.9 (39.0 to 54.0$)$ & $<0.001$ \\
\hline Number of tests and examinations & $14.0(11.4$ to 16.6$)$ & 22.1 (13.9 to 31.3$)$ & 0.052 \\
\hline
\end{tabular}

ICU, intensive care unit; LOS, length of stay. 


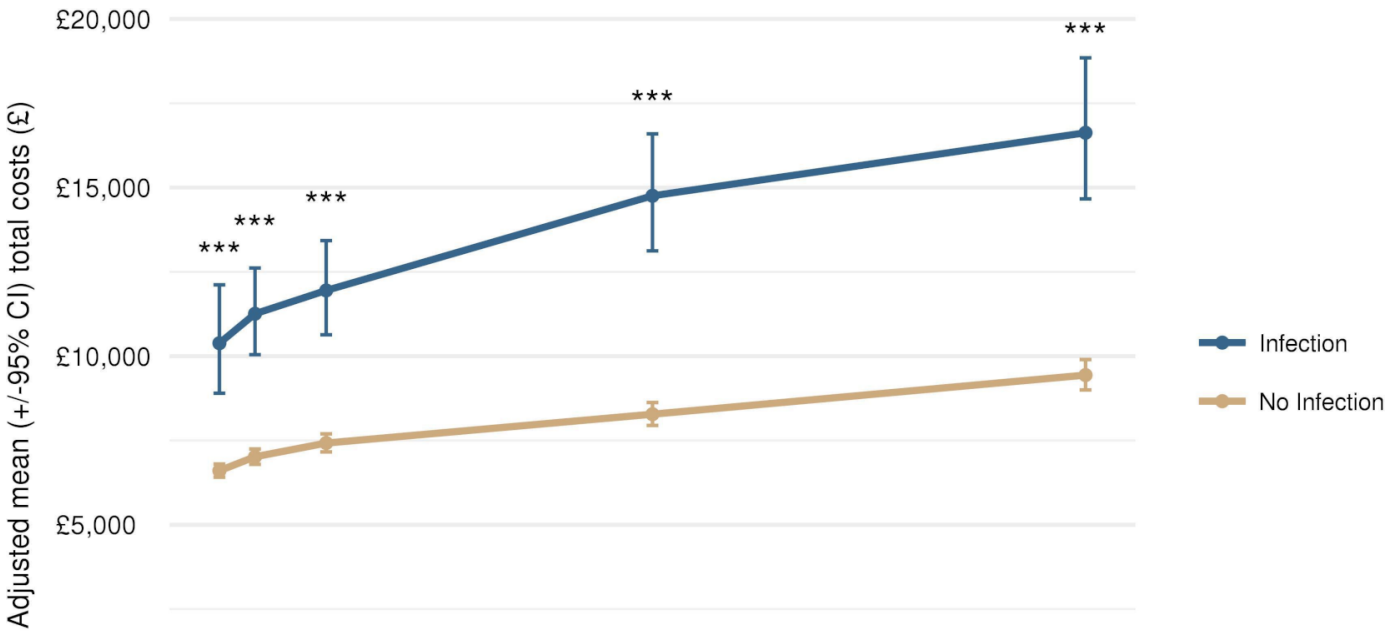

$£ 0$

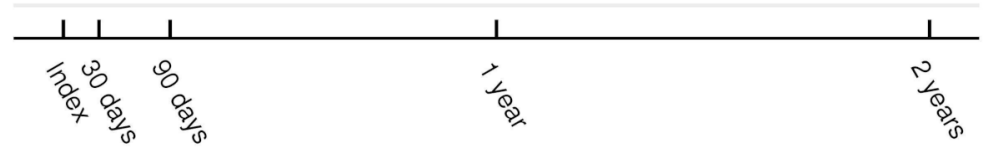

Follow-up time post-discharge of the index stay

Figure 4 Total costs from index stay to 2 -year follow-up; ${ }^{* \star} p<0.001$. Data plotted are means $\pm 95 \% \mathrm{Cl}$.

the $10.5 \%$ rate reported in a 2014 meta-analysis. ${ }^{5}$ Mean inpatient costs measured after 1 year were predicted to be $80 \%$ higher (£6056) for patients with infection compared with those without infection, while overall costs were $78 \%$ higher. The greatest cost drivers were hospital LOS (109\% increase at 1 year), readmissions (odds of being readmitted increased by 5.18 times at 1 year) and reoperations (odds of reoperation increased by 2.47 times at 1 year). The 2-year follow-up in this study meant that we were able to capture changes in resource use over time associated with infection, such as readmission and reoperation. The findings of this study highlight the substantial impact on healthcare resource utilisation and costs to the English NHS, from both the hospital and primary care perspective.

This study is the first to quantify the additional healthcare resource burden of infections following tibial fractures treated with IMN in England with a long-term perspective, which includes inpatient, hospital outpatient and primary care parameters. Differences in healthcare systems, patient populations and treatment pathways make direct comparison with studies from other countries challenging; however, our findings are in line with results of studies from Belgium and Denmark. ${ }^{10}{ }^{11}$ Hoekstra et al demonstrated five times higher healthcare costs and six times longer LOS for open tibial shaft fracture patients with deep infection versus those without infection in Belgium. ${ }^{10}$ Although the magnitude of the increase in costs and LOS observed in our study is not as substantial, differences in patient populations may be a contributing factor, as Hoekstra et al did not limit their study population to intramedullary nail fixation. ${ }^{10}$ In their Danish study, Olesen et al estimated a $60 \%$ increase in direct costs and an $80 \%$ increase in LOS resulting from infected open tibial fractures ${ }^{11}$ consistent with the magnitude of the increase observed in the current study; absolute LOS (74 days) and direct healthcare costs $(€ 81$ 155) in the presence of infection were substantially higher than in our study, however, which may in part reflect the most severe types of wounds considered in the Danish study, all of which were open fractures and $80 \%$ of which were GustiloAnderson classification 3. Furthermore, a US-study found that surgical site infections nearly doubled inpatient costs to $\$ 109000$ in patients with isolated fractures. ${ }^{24}$

Surgical site infections remain one of the most challenging complications in trauma surgery. ${ }^{25}$ Over the past decades, surgical site infection incidence has decreased, especially deep infections in patients with open tibial fractures. ${ }^{26}$ The question remained whether these rates could be decreased further. Still, no infections occurred in two studies in complex tibial fracture patients treated with antibiotic coated intramedullary tibia nails. ${ }^{27} 28$ Based on consensus opinions, they may be a promising option for prevention of surgical site infections in open fractures or revision cases. ${ }^{29}$ Other approaches to prevent infections through local delivery of antibacterials were based on specialised biomaterials formulated as additives in bone void fillers such as bone cement or bacteriostatic bone substitute materials. ${ }^{253031}$ Moreover, in order to prevent infections, open fractures should be managed according to the UK National Institute for Health and Care Excellence guideline and the Open fracture British Orthopaedic Association Standard for Trauma and Orthopedics (BOAST). ${ }^{32} 33$

This study is subject to the following limitations: (1) potential bias in the patient population as we only considered patients with complete follow-up, thus excluding very severe patients with short life expectancy or with few 
A

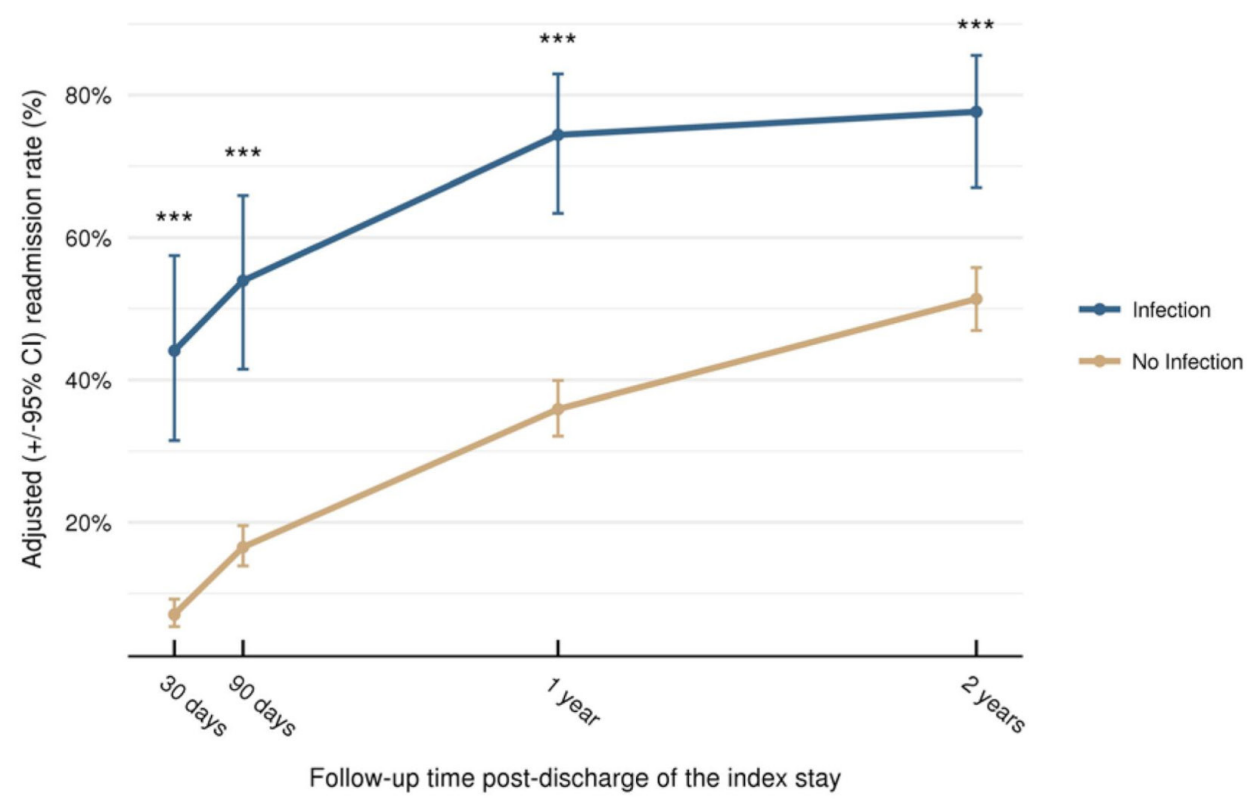

B

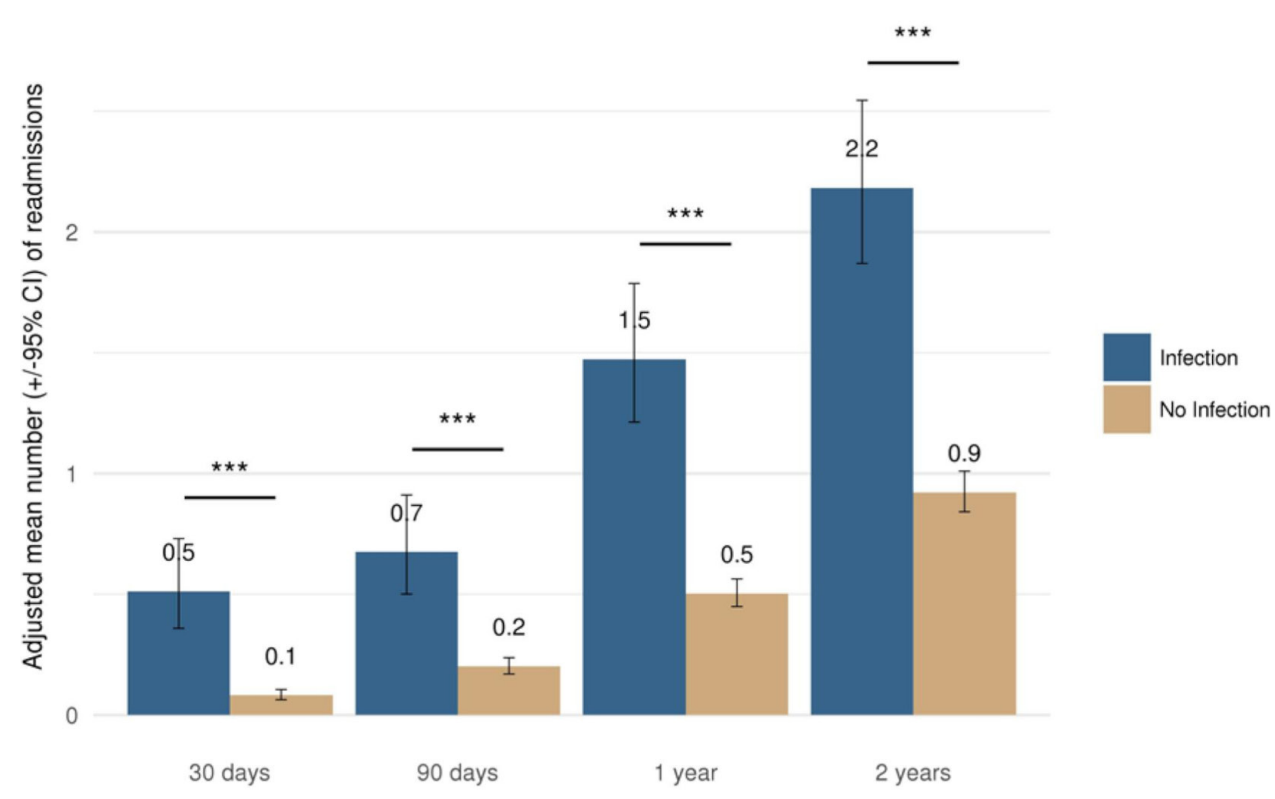

Follow-up time post-discharge of the index stay

Figure 5 Readmission (adjusted) according to follow-up time: (A) readmission rate and (B) mean number of readmissions per patient; ${ }^{* \star *} \mathrm{p}<0.001$. Data plotted are means $\pm 95 \% \mathrm{Cl}$.

comorbidities, limiting the generalisability of the findings to this subgroup; (2) identification of relevant patients for inclusion in the study was based on OPCS, ICD-10 and primary care-based read codes. The data may be susceptible to coding errors and misclassifications. Surgical site infections were defined following the Centers for Disease Control and Prevention (CDC) criteria. ${ }^{34}{ }^{35}$ Recently it became clear that the CDC definition for infection probably is not sufficient to define fracture-related infections. One important reason is the fact that the subdivision of infection into superficial and deep infection is arbitrary. ${ }^{36}$ However, the use of the CDC definition was standard during our study period (2003-2017); (3) medication use was costed as recorded in CPRD, that is, averaged to the cost of the drug family/British National Formulary sub-paragraph; (4) dispensing costs were not included; (5) outpatient specialties from CPRD did not always exactly match outpatient specialty categories from NHS Reference Costs; when there was not an exact match, the closest matching specialty was chosen; (6) costs were not directly available from the CPRD dataset and hence unit costs had to be sourced from published national sources for primary and secondary care and for drug prices; (7) economic assessment was limited to direct healthcare 
A

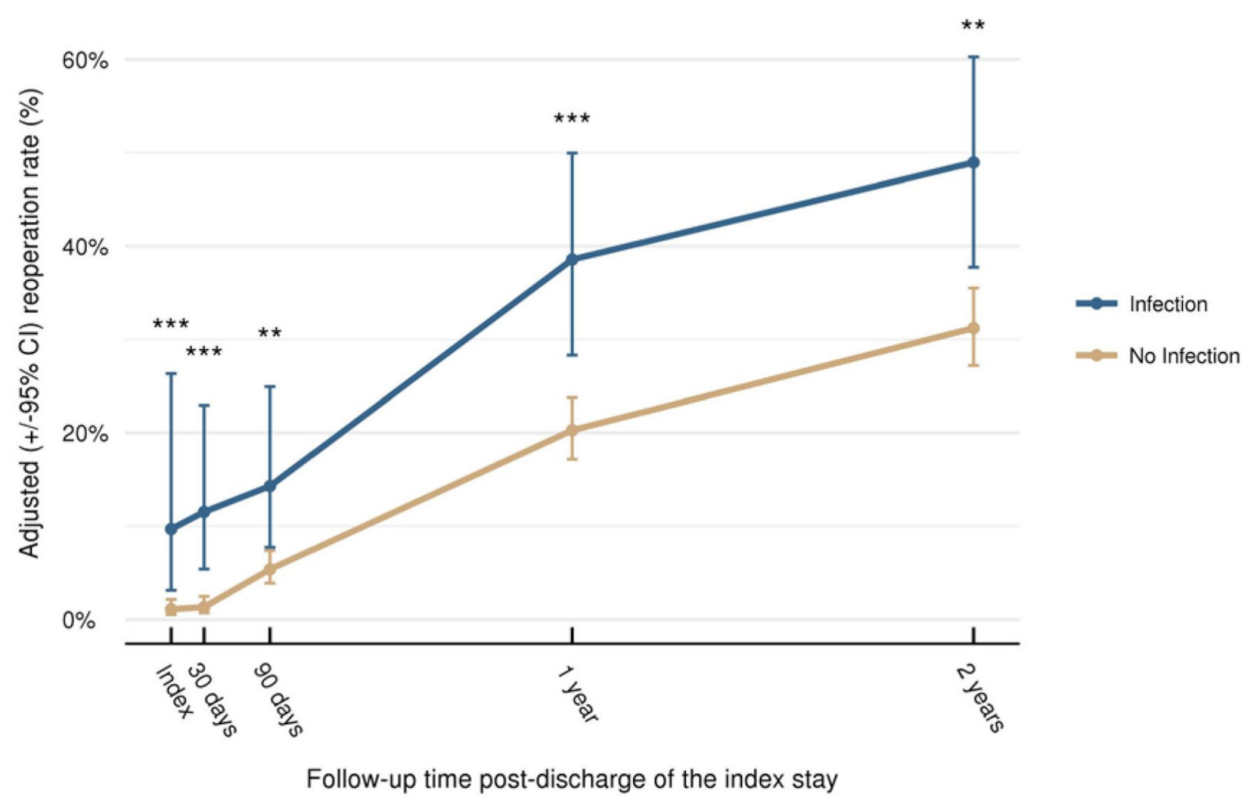

B

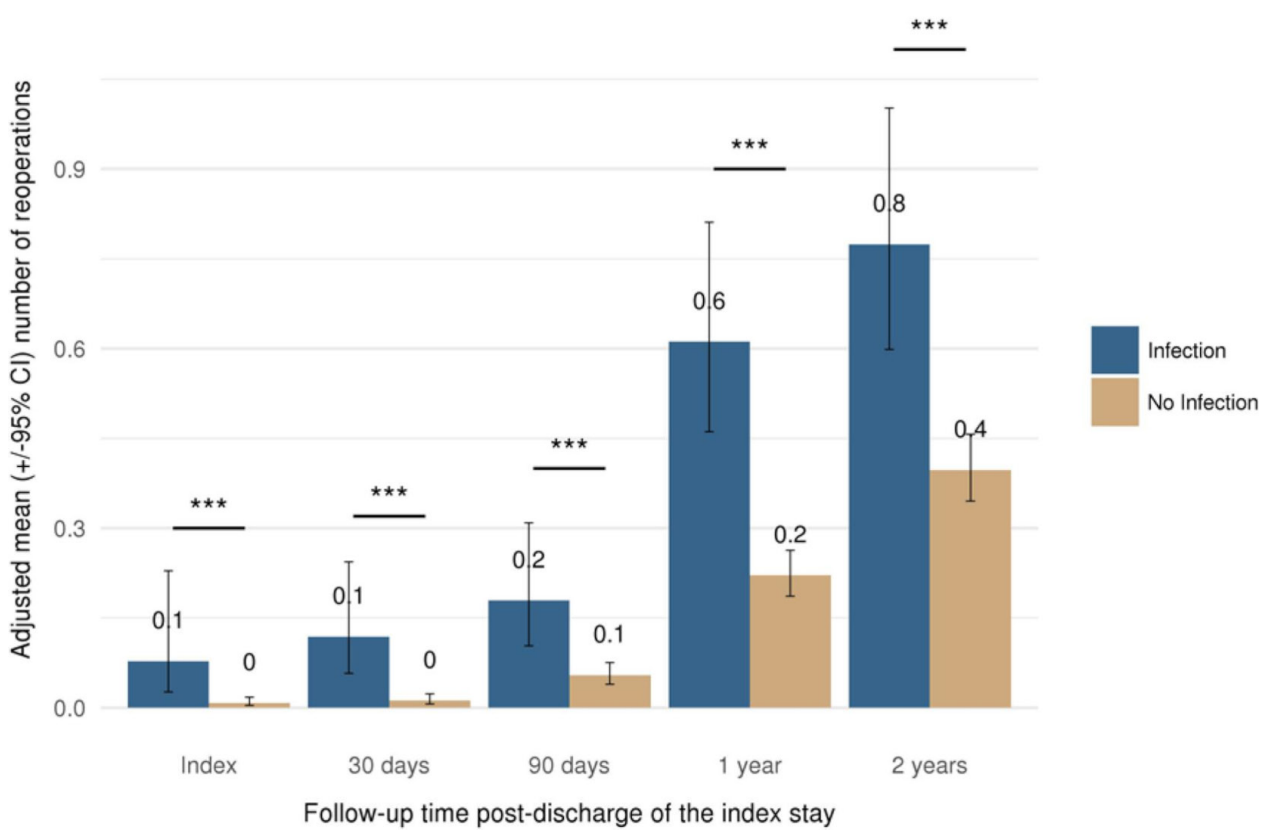

Figure 6 Reoperation (adjusted) according to follow-up time: (A) reoperation rate and (B) mean number of reoperations per patient $\left({ }^{* *} \mathrm{p}<0.01,{ }^{* \star *} \mathrm{p}<0.001\right)$. Data plotted are means $\pm 95 \% \mathrm{Cl}$.

costs while infections could lead to permanent functional loss and potentially increase in secondary costs; ${ }^{25}$ and (8) all potential confounders could not be adjusted for, limiting the association between increased healthcare resource utilisations and costs with surgical site infections.

Our study provides important evidence as to the shortterm to mid-term direct economic consequences of infection following tibial fractures. By increasing the sample size, the impact of infection type (superficial/deep) and fracture type (open/closed) could have been explored more robustly. Additional validation of clinical codes used to identify relevant data would have allowed us to account for any potential variation in clinical coding practice. Broadening the perspective to include indirect costs would allow the additional burden of infection to be established, such as rehabilitation and absenteeism.

\section{CONCLUSION}

This study confirms that infection presents a substantial healthcare burden, leading to significantly increased hospital LOS, need for hospital readmission and 
reoperation, and increased use of general practictioners and other primary care resources. As such there exists an unmet need for alternative medical technologies and infection prevention strategies that could help to reduce infections in tibial shaft fractures and reduce costs. Our study indicates that the potential mid-term (1-2 years) saving to the English NHS of is around $£ 6500$ per patient.

\section{Author affiliations}

${ }^{1}$ Department of Health Economics and Market Access, Johnson and Johnson Medical Devices, Issy-les-Moulineaux, France

${ }^{2}$ Department of Real World Analytics and Research, Johnson and Johnson Medical

Devices, New Brunswick, New Jersey, USA

${ }^{3}$ Department of Health Economics and Market Access, DePuy Synthes, Zuchwil, Switzerland

${ }^{4}$ Department of Health Economics and Market Access, Johnson and Johnson Medical Devices, Somerville, New Jersey, USA

${ }^{5}$ Academic Department of Trauma and Orthopaedics, Leeds Teaching Hospitals NHS Trust, Leeds, UK

${ }^{6}$ School of Medicine, University of Leeds, Leeds, UK

Acknowledgements We thank James Woolnough (Mtech Access) who provided medical writing services in the preparation of the manuscript, funded by DePuy Synthes.

Contributors Study conception and design: TG, PVG, CEH, KP, CT and AC. Acquisition of data: TG, PVG, CT and AC. Data analysis: TG, CT and AC. Interpretation of data and results: TG, PVG, CEH, KP, CT and AC. Drafting of manuscript: TG, PVG, CEH, KP, CT and AC. Critical revision: TG, PVG, CEH, KP, CT and AC. Project management: KP.

\section{Funding This study was sponsored by DePuy Synthes.}

Competing interests PVG received honoraria from DePuy Synthes for his involvement in this study. TG, AC, CT and CEH are employees of Johnson and Johnson Medical Devices. KP is an employee of DePuy Synthes. The funding corporations could have affected the study design, analysis and manuscript writing; but authors owned final decisions.

\section{Patient consent for publication Not required.}

Ethics approval The study protocol was approved by the Independent Scientific Advisory Committee for Medicines and Healthcare products Regulatory Agency database research (ISAC) on 27 November 2017 (ISAC Protocol: 17-132R). General ethical approval for observational research using the CPRD with approval from the ISAC was granted by a Health Research Authority Research Ethics Committee (East Midlands-Derby; reference number: 05/MRE04/87).

Provenance and peer review Not commissioned; externally peer reviewed.

Data availability statement Data may be obtained from a third party and are not publicly available. The data that support the findings of this study are available from Clinical Practice Research Datalink (CPRD), but restrictions apply to the availability of these data, which were used under license for the current study, and so are not publicly available.

Open access This is an open access article distributed in accordance with the Creative Commons Attribution Non Commercial (CC BY-NC 4.0) license, which permits others to distribute, remix, adapt, build upon this work non-commercially, and license their derivative works on different terms, provided the original work is properly cited, appropriate credit is given, any changes made indicated, and the use is non-commercial. See: http://creativecommons.org/licenses/by-nc/4.0/.

\section{ORCID iD}

Thibaut Galvain http://orcid.org/0000-0002-0412-249X

\section{REFERENCES}

1 Duan X, Al-Qwbani M, Zeng Y, et al. Intramedullary nailing for tibial shaft fractures in adults. Cochrane Database Syst Rev 2012;1:CD008241.

2 Elniel AR, Giannoudis PV. Open fractures of the lower extremity: current management and clinical outcomes. EFORT Open Rev 2018;3:316-25.
3 Kanakaris NK, Tosounidis TH, Giannoudis PV. Surgical management of infected non-unions: an update. Injury 2015;46 Suppl 5:S25-32.

4 Smith EJ, Kuang X, Pandarinath R. Comparing hospital outcomes between open and closed tibia fractures treated with intramedullary fixation. Injury 2017;48:1609-12.

5 Craig J, Fuchs T, Jenks M, et al. Systematic review and metaanalysis of the additional benefit of local prophylactic antibiotic therapy for infection rates in open tibia fractures treated with intramedullary nailing. Int Orthop 2014;38:1025-30.

6 Metsemakers WJ, Kortram K, Morgenstern M, et al. Definition of infection after fracture fixation: a systematic review of randomized controlled trials to evaluate current practice. Injury 2018;49:497-504.

7 Centre for Disease Control. National healthcare safety network (NHSN) patient safety component manual, 2018. Available: https:// www.cdc.gov/nhsn/pdfs/validation/2018/pcsmanual_2018-508.pdf

8 Auston DA, Meiss J, Serrano R, et al. Percutaneous or open reduction of closed tibial shaft fractures during intramedullary nailing does not increase wound complications, infection or nonunion rates. J Orthop Trauma 2017;31:215-9.

9 Metsemakers W-J, Handojo K, Reynders P, et al. Individual risk factors for deep infection and compromised fracture healing after intramedullary nailing of tibial shaft fractures: a single centre experience of 480 patients. Injury 2015;46:740-5.

10 Hoekstra H, Smeets B, Metsemakers W-J, et al. Economics of open tibial fractures: the pivotal role of length-of-stay and infection. Health Econ Rev 2017;7:32.

11 Olesen UK, Pedersen NJ, Eckardt $\mathrm{H}$, et al. The cost of infection in severe open tibial fractures treated with a free flap. Int Orthop 2017;41:1049-55.

12 Herrett E, Gallagher AM, Bhaskaran K, et al. Data resource profile: clinical practice research datalink (CPRD). Int J Epidemiol 2015;44:827-36.

13 Boyle S. United Kingdom (England): health system review. Health Syst Transit 2011;13:1-483.

14 Bojke C, Grašic K, Street A. How should Hospital reimbursement be refined to support concentration of complex care services? Health Econ 2018;27:e26-38.

15 Canavan C, West J, Card T. Calculating total health service utilisation and costs from routinely collected electronic health records using the example of patients with irritable bowel syndrome before and after their first gastroenterology appointment. Pharmacoeconomics 2016;34:181-94.

16 National Health Service. Costing - HRG4+ 2017/18 reference costs grouper, 2017. Available: https://digital.nhs.uk/services/nationalcasemix-office/downloads-groupers-and-tools/costing-hrg4-201718-reference-costs-grouper

17 NHS Improvement. National schedule of reference costs 2016/17, 2017. Available: https://improvement.nhs.uk/resources/referencecosts/

18 Achana FA, Fleming KM, Tata LJ, et al. Peripartum hysterectomy: an economic analysis of direct healthcare costs using routinely collected data. BJOG 2018;125:874-83.

19 Danese MD, Gleeson M, Griffiths RI, et al. Methods for estimating costs in patients with hyperlipidemia experiencing their first cardiovascular event in the United Kingdom. J Med Econ 2017;20:931-7.

20 NHS Department of Health. A simple guide to payment by results, 2012. Available: https://assets.publishing.service.gov.uk/ government/uploads/system/uploads/attachment_data/file/213150/ PbR-Simple-Guide-FINAL.pdf

21 NHS England and NHS Improvement. NHS national tariff payment system 2017/18 and 2018/19. Available:https://improvement.nhs.uk/ documents/1044/2017-18_and_2018-19_National_Tariff_Payment_ System.pdf

22 Curtis L, Burns A. Unit costs of health and social care, 2017. Available: https://www.pssru.ac.uk/project-pages/unit-costs/unitcosts-2017/ [Accessed 9 Nov 2018].

23 NHS Digital. Prescription cost analysis - England, 2017, 2018. Available: https://digital.nhs.uk/data-and-information/publications/ statistical/prescription-cost-analysis/prescription-cost-analysisengland-2017

24 Thakore RV, Greenberg SE, Shi H, et al. Surgical site infection in orthopedic trauma: a case-control study evaluating risk factors and cost. J Clin Orthop Trauma 2015;6:220-6.

25 Metsemakers WJ, Kuehl R, Moriarty TF, et al. Infection after fracture fixation: current surgical and microbiological concepts. Injury 2018;49:511-22.

26 Ktistakis I, Giannoudi M, Giannoudis PV. Infection rates after open tibial fractures: are they decreasing? Injury 2014;45:1025-7.

27 Metsemakers WJ, Reul M, Nijs S. The use of gentamicin-coated nails in complex open tibia fracture and revision cases: a retrospective 
analysis of a single centre case series and review of the literature. Injury 2015;46:2433-7.

28 Fuchs T, Stange R, Schmidmaier G, et al. The use of gentamicincoated nails in the tibia: preliminary results of a prospective study. Arch Orthop Trauma Surg 2011;131:1419-25.

29 Metsemakers W-J, Fragomen AT, Moriarty TF, et al. Evidencebased recommendations for local antimicrobial strategies and dead space management in Fracture-Related infection. J Orthop Trauma 2020;34:18-29.

30 Buchholz HW, Engelbrecht H. [Depot effects of various antibiotics mixed with Palacos resins]. Chirurg 1970;41:511-5.

31 van Gestel NAP, Geurts J, Hulsen DJW, et al. Clinical applications of S53P4 bioactive glass in bone healing and osteomyelitic treatment: a literature review. Biomed Res Int 2015;2015:1-12.
32 National Institute for Health and Care Excellence. Fractures (complex): assessment and management, 2017. Available: https:// www.nice.org.uk/guidance/ng37

33 British Orthopaedic Association. BOAST - Open fractures, 2017. Available: https://www.boa.ac.uk/resources/boast-4-pdf.html

34 Mangram AJ, Horan TC, Pearson ML, et al. Guideline for prevention of surgical site infection, 1999. centers for disease control and prevention (CDC) hospital infection control practices Advisory Committee. Am J Infect Control 1999;27:97-132

35 Horan TC, Gaynes RP, Martone WJ, et al. Cdc definitions of nosocomial surgical site infections, 1992: a modification of CDC definitions of surgical wound infections. Infect Control Hosp Epidemiol 1992;13:606-8.

36 Metsemakers WJ, Morgenstern M, McNally MA, et al. Fracturerelated infection: a consensus on definition from an international expert group. Injury 2018;49:505-10. 